\title{
Nanoparticles for the Induction of Antigen-Specific Immunological Tolerance
}

\author{
Takashi Kei Kishimoto* and Roberto A. Maldonado \\ Selecta Biosciences Inc., Watertown, MA, United States
}

Antigen-specific immune tolerance has been a long-standing goal for immunotherapy for the treatment of autoimmune diseases and allergies and for the prevention of allograft rejection and anti-drug antibodies directed against biologic therapies. Nanoparticles have emerged as powerful tools to initiate and modulate immune responses due to their inherent capacity to target antigen-presenting cells (APCs) and deliver coordinated signals that can elicit an antigen-specific immune response. A wide range of strategies have been described to create tolerogenic nanoparticles (tNPs) that fall into three broad categories. One strategy includes tNPs that provide antigen alone to harness natural tolerogenic processes and environments, such as presentation of antigen in the absence of costimulatory signals, oral tolerance, the tolerogenic environment of the liver, and apoptotic cell death. A second strategy includes tNPs that carry antigen and simultaneously target tolerogenic receptors, such as pro-tolerogenic cytokine receptors, aryl hydrocarbon receptor, FAS receptor, and the CD22 inhibitory receptor. A third strategy includes tNPs that carry a payload of tolerogenic pharmacological agents that can "lock" APCs into a developmental or metabolic state that favors tolerogenic presentation of antigens. These diverse strategies have led to the development of tNPs that are capable of inducing antigen-specific immunological tolerance, not just immunosuppression, in animal models. These novel tNP technologies herald a promising approach to specifically prevent and treat unwanted immune reactions in humans. The first tNP, SEL-212, a biodegradable synthetic vaccine particle encapsulating rapamycin, has reached the clinic and is currently in Phase 2 clinical trials. This article was submitted to Immunological Tolerance and Regulation,

a section of the journal

Frontiers in Immunology

Received: 12 October 2017

Accepted: 26 January 2018

Published: 20 February 2018

Citation:

Kishimoto TK and Maldonado RA (2018) Nanoparticles for the Induction of Antigen-Specific Immunological Tolerance.

Front. Immunol. 9:230. doi: 10.3389/fimmu.2018.00230

Keywords: nanoparticles, immunological tolerance, rapamycin, tolerogenic dendritic cells, regulatory $\mathrm{T}$ cells

\section{INTRODUCTION}

The central function of the immune system is the maintenance of immunological tolerance to selfcomponents and innocuous exogenous antigens while eliminating malignant cells and dangerous pathogens. Immunological tolerance, defined as the absence of immunity to an antigen even in the presence of otherwise immunogenic stimuli, is achieved through a combination of processes that lead to the elimination or inactivation of immune cells specific for the antigen and the development of regulatory $\mathrm{T}$ cells (Tregs). The first and most impactful selection process, called central tolerance, eliminates lymphocytes recognizing self-antigens or leads to the differentiation of natural Tregs in the thymus. Autoreactive cells can escape this process and survive to join the repertoire of mature circulating lymphocytes. This pool of potentially dangerous cells can be further tolerized by 
encountering their cognate antigen in absence of immunogenic signals leading to anergy or the induction of adaptive Tregs and the establishment of peripheral tolerance (1). For example, autoreactive lymphocytes specific for components of the nervous system can be identified in the circulation of animals and humans $(2,3)$. These cells remain dormant and checked by regulatory $\mathrm{T}$ and B cells. Similarly, most "foreign" gut-associated antigens (microbial or dietary) are well tolerated and do not trigger pathogenic immune responses. However, in presence of strong and persistent stimuli, lymphocytes specific for these antigens can break tolerance and launch attacks against self-components and innocuous antigens triggering disorders such as autoimmune diseases and food allergies, respectively.

Antigen-presenting cells (APCs), such as dendritic cells (DCs), are at the crossroads of immunity and tolerance (Figure 1). APCs sample and process antigens in the context of multiple complex cues from their environment. The pivotal signals allowing APCs to instruct lymphocytes to acquire the expression of costimulatory molecules and support the development of immunity have been categorized as "danger signals." Such signals include pathogen-associated molecular patterns (4), damage-associated molecular patterns (5), changes in the tissue metabolic state (6), inflammatory cytokines (7), and costimulatory-molecule ligands (8). Stimulation of APCs triggers a "maturation" program that includes activation of the NF kappa $B(N F-\kappa B)$ and mammalian target of rapamycin (mTOR) pathways and leads to metabolic changes and upregulation of costimulatory molecules, such as such as CD80, CD86, and CD40, and production of pro-inflammatory cytokines (9-11). By contrast, antigen presentation in the absence of such costimulatory signals results in anergy and tolerance $(12,13)$. APCs capable of tolerance induction include macrophages, B cells and DCs (14-17). Animals lacking DCs have a general failure in the establishment of self-tolerance, resulting in autoimmune conditions (18-22). Whether an immature or steadystate phenotype is required for DCs to induce tolerance is still a matter of debate. Recently the notion that tolerance is established by DCs that undergo incomplete maturation has been challenged by findings that tolerogenic DCs require transcriptional and epigenetic programs distinct from both steady-state (immature) and activated (mature) DCs (14, 19, 22-24). Furthermore, there is conflicting evidence about the phenotypic characteristics that define tolerogenic DCs induced by immunomodulatory drugs. For example, induction of tolerogenic capacities by treating DCs in vitro or in vivo with free or encapsulated rapamycin results in induced tolerogenic DCs (itDCs) of different phenotypes and maturation characteristics (e.g., expression of MHC-CLII and costimulatory molecules) (14, 25-30).

Regardless of the specifics of their phenotype, APCs constitute an ideal target to manipulate immune responses (Figure 1). Nanoparticles have unique properties that make them well suited to target APCs and deliver instructions that can modulate the nature of an antigen-specific immune response in vivo (31-35).

\section{WHY NANOPARTICLES?}

The immune system has evolved to capture and interrogate virus-like (nanosized) particles $(36,37)$. Such nanoparticulates are filtered out and accumulate in lymphoid organs, such lymph nodes and the spleen, and the liver. This scavenger task is performed by APCs that are adept at phagocytosing and eliminating debris in the extracellular environment. Synthetic nanoparticles of a wide array of materials in the range of $50 \mathrm{~nm}$ to $1 \mu \mathrm{m}$ of size are readily phagocytosed by APCs $(31,32,36-38)$. The display of multimerized antigen on nanoparticles has been shown to be inherently immunogenic, similar to particulate or aggregated antigen $(36,37,39)$. Encapsulation or conjugation of antigens (both peptides and entire proteins) can lead to their presentation as a multimerized complex that has the potential to directly engage and cross-link of B cell receptors (BCRs), resulting in the activation of humoral immunity. Indeed, many particle-based vaccines exploit these principles (encapsulation and multimeric display) to induce protective humoral immunity (38).

To engineer nanocarriers for the induction of tolerance, we and others have use materials and components that provide tolerogenic signaling to APCs or harness natural tolerogenic processes to override the inherently immunogenic nature of antigen-bearing nanocarriers. The usage of synthetic tolerogenic nanoparticles (tNPs) confers several important advantages compared with other strategies to induce tolerance (Table 1). Nanoparticles can employ a wide range of materials that can be optimized for various functions and can carry a diverse payload of antigens and immunomodulators to deliver coordinated messages to the immune system.

This review will focus on nanoparticle approaches for the induction of antigen-specific immune tolerance. We define antigen-specific tolerance as the absence of immune response against an immunogenic target antigen, maintenance of tolerance after cessation of treatment, and retention of the ability to mount an immune response to an unrelated antigen. There have been three broad approaches to achieving antigen-specific immune tolerance with nanoparticles (Figure 2): (1) tNPs that provide antigen alone to harness natural tolerogenic processes or environments, (2) tNPs that provide antigen while targeting pro-tolerogenic receptors, and (3) tNPs that use pharmacological immunomodulators to force or "lock-in" a tolerogenic immune response against a target antigen. Nanoparticle delivery of immunomodulators, in the absence of a specific target antigen, for the treatment of autoimmune diseases and prevention of graft rejection is beyond the scope of this review, although it is notable that this approach has demonstrated durable disease modification in animal models (73-76). Similarly, nanoparticles that skew the immune response in an antigen-specific manner, such as Th1 polarizing nanoparticles for the treatment of Th2mediated allergic diseases (77), are also not included in this review.

\section{tNP PROPERTIES}

Key attributes of nanoparticles affecting their function include material composition, size and charge. Materials for tNP manufacturing are diverse, and the choice depends on the desired function and compatibility with the payload. Three broad categories of materials include metals, liposomes, and synthetic and natural polymers. Metal and metal-oxide nanoparticles have 


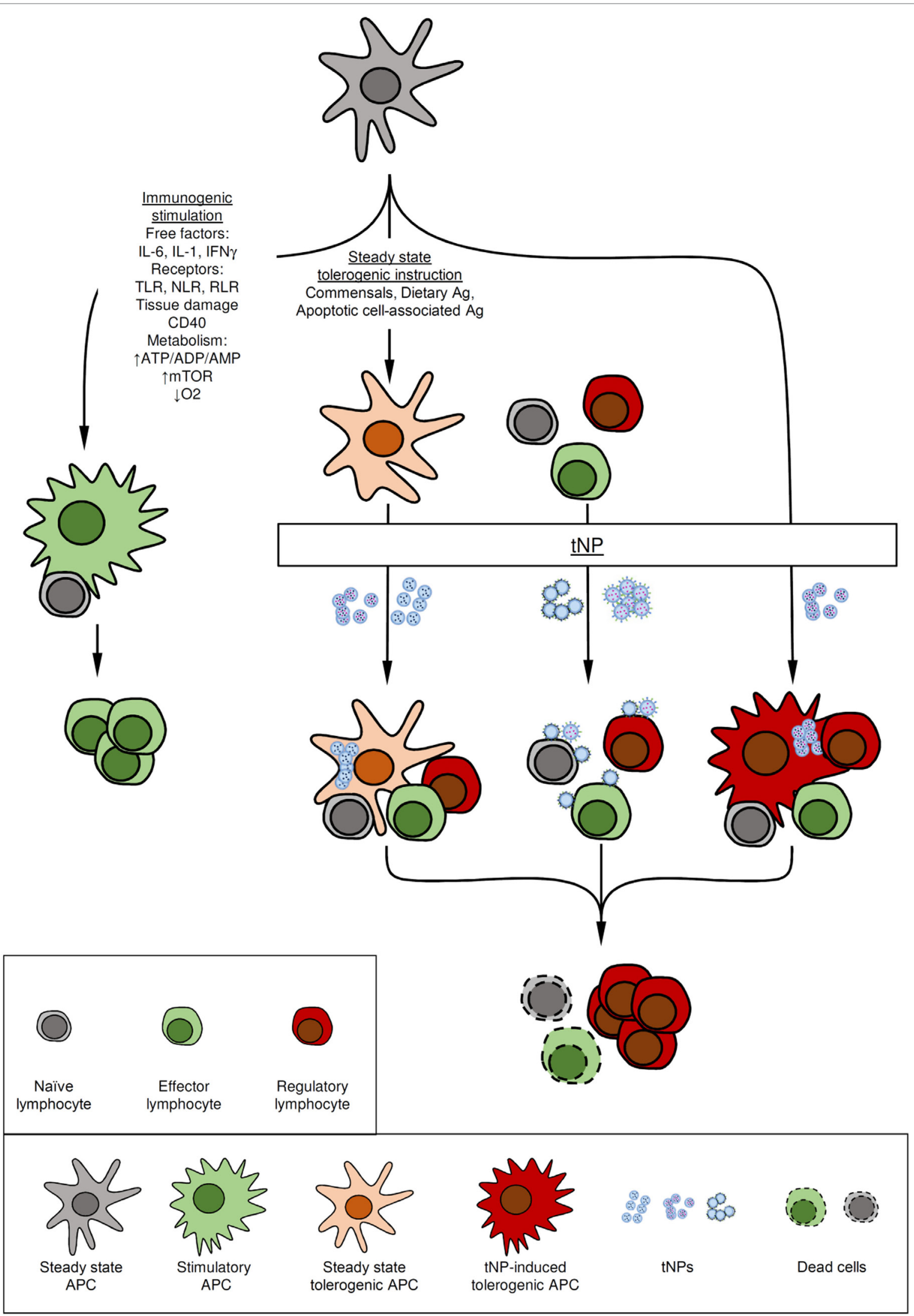

FIGURE 1 | Continued 
FIGURE 1 | Mode of action of tolerogenic nanoparticles (tNPs). Antigen-presenting cells (APCs) play a major function in the immune system by integrating cues from the environment to promote immunity or tolerance. (A) Immunogenic stimuli such as cytokines, microbial components recognized by toll-like receptors (TLRs), NOD-like receptors (NLRs), RIG-I-like receptor (RLR), and changes in the metabolic state of the tissue can activate APCs to induce immunity. (B) At steady-state immature APCs that capture self and innocuous antigens, such as those from commensal bacteria, present antigen in the absence of costimulation to induce or maintain tolerance. (C) Some tolerogenic NPs harness these natural tolerogenic processes by targeting tolerogenic delivery routes (oral tolerance), tolerogenic environments (liver), or mimicking apoptotic cells. (D) Other tNPs actively promote immune tolerance by employing pharmacological agents to induce tolerogenic dendritic cells. (E) Lymphocytes can also be targeted directly by tNPs that engage antigen-specific receptors in absence of costimulation or by targeting tolerogenic receptors. In all cases, tolerance is mediated by the preventing the activation of or eliminating antigen-specific cells both (naïve or effector) and/or the expansion of regulatory lymphocytes.

TABLE 1 | Tolerogenic nanoparticle (tNP) composition, mechanism, and characteristics.

\begin{tabular}{|c|c|c|c|}
\hline tNP composition & Mechanism & Characteristics & Reference \\
\hline $\begin{array}{l}\text { Peptide-major histocompatibility complex } \\
\text { (MHC) complexes on metal-oxide NPs or } \\
\text { peptide-MHC complexes plus anti-Fas } \\
\text { ligand antibody }\end{array}$ & $\begin{array}{l}\text { Antigen presentation w/o } \\
\text { costimulation on synthetic antigen- } \\
\text { presenting cell. Anti-FAS ligand } \\
\text { antibody delivers apoptotic signal }\end{array}$ & $\begin{array}{l}\text { Direct action on effector T cells, but requires complex } \\
\text { manufacturing. Restricted to peptide antigens (antigen } \\
\text { selection risk). Non-biodegradable }\end{array}$ & $(40-42)$ \\
\hline $\begin{array}{l}\text { Protein or DNA-encoded antigen in } \\
\text { poly(lactic-co-glycolic acid) (PLGA) or } \\
\text { chitosan NPs }\end{array}$ & Oral tolerance & $\begin{array}{l}\text { Ease of delivery via oral route. However, poor history } \\
\text { of translation for oral tolerance }\end{array}$ & $(43-45)$ \\
\hline $\begin{array}{l}\text { Peptides conjugated to polystyrene, } \\
\text { PLGA, or poly(maleic anhydride-alt-1- } \\
\text { octadecene) nanoparticles }\end{array}$ & $\begin{array}{l}\text { Mimic apoptotic cells; target } \\
\text { tolerogenic niche via MARCO+ } \\
\text { macrophages in spleen or liver } \\
\text { sinusoidal cells }\end{array}$ & $\begin{array}{l}\text { Simple composition, but restricted to peptides and i.v. } \\
\text { dosing. Potential to be stimulatory in inflammatory setting }\end{array}$ & $(46-52)$ \\
\hline $\begin{array}{l}\text { Antigen encapsulated in liposomes } \\
\text { containing phosphatidylserine (PS) }\end{array}$ & $\begin{array}{l}\text { Mimic apoptotic cells TAM? } \\
\text { Scavenger receptor-mediated } \\
\text { uptake by macrophages }\end{array}$ & $\begin{array}{l}\text { PS-binding scavenger receptors trigger TAM? receptors } \\
\text { and tolerogenic response }\end{array}$ & $(53-57)$ \\
\hline $\begin{array}{l}\text { NPs encapsulating tolerogenic } \\
\text { cytokines and antigen }\end{array}$ & $\begin{array}{l}\text { Anti-inflammatory cytokines create a } \\
\text { tolerogenic microenvironment? }\end{array}$ & $\begin{array}{l}\text { Complex manufacturing. Potential to create autoreactive } \\
\text { immune response to endogenous cytokines }\end{array}$ & $(58-60)$ \\
\hline $\begin{array}{l}\text { Liposomes presenting antigen } \\
\text { and CD22 ligand }\end{array}$ & $\begin{array}{l}\text { Induce antigen-specific B cell } \\
\text { tolerance and deletion }\end{array}$ & $\begin{array}{l}\text { Direct action on specific B cells. CD22 ligand is a complex } \\
\text { sugar that is difficult to manufacture. Requires protein antigen }\end{array}$ & $(61,62)$ \\
\hline $\begin{array}{l}\text { Gold particles presenting peptide } \\
\text { antigen and aryl hydrocarbon agonist }\end{array}$ & $\begin{array}{l}\text { Trigger aryl hydrocarbon receptor } \\
(\mathrm{AHR}) \text { pathway }\end{array}$ & $\begin{array}{l}\text { Utilizes an immunomodulator (AHR agonist) to lock in tolerogenic } \\
\text { response. Restricted to peptides? Non-biodegradable }\end{array}$ & $(63,64)$ \\
\hline $\begin{array}{l}\text { Liposomes containing peptide antigen } \\
\text { and antigen }\end{array}$ & Inhibit NF kappa B (NF-кB) pathway & $\begin{array}{l}\text { Utilizes an immunomodulator (NF-кB inhibitor) to lock in tolerogenic } \\
\text { response. Works with protein antigens and s.c. or i.v. route }\end{array}$ & (65) \\
\hline $\begin{array}{l}\text { Polylactic acid/PLGA NPs containing } \\
\text { rapamycin + antigen (encapsulated } \\
\text { or free) }\end{array}$ & $\begin{array}{l}\text { Induce tolerogenic dendritic cells by } \\
\text { inhibition of mammalian target } \\
\text { of rapamycin pathway }\end{array}$ & $\begin{array}{l}\text { Utilizes an immunomodulator (rapamycin) to lock in tolerogenic } \\
\text { response. Works with both protein and peptide antigens and } \\
\text { s.c. or i.v. route. Human proof of clinical activity demonstrated }\end{array}$ & $(30,66-72)$ \\
\hline
\end{tabular}

been used for theranostics with capacity to carry antigens, targeting ligands, and immunomodulators on the particle surface (40, $41,63,64)$. These particles are very stable but typically require conjugation of the payload which may limit the application to certain molecules. A key disadvantage is that metal particles are not biodegradable, and hence accumulation may become a safety issue. Liposomes have been used in the clinic to deliver small molecule drugs and nucleic acids. Liposomes can incorporate various different phospholipids to create a membrane bilayer. The addition of cholesterol can alter the membrane fluidity of the lipid bilayer, which enables clustering of surface molecules upon interaction with target cells (62). In addition, phosphatidylserine (PS) lipids can be incorporated to target scavenger receptors involved in the phagocytosis of apoptotic cells (53). Liposomes can be adapted to incorporate various payloads with different physicochemical properties that get released after the liposome fuses with a cell membrane or after degradation in endosomes. The manufacturing of liposomes through a low shear extrusion method allows for encapsulation of proteins while minimizing the risk of denaturation. Molecules can be conjugated to the surface of liposomes but also hydrophilic molecules are amenable for encapsulation within the aqueous core of liposomes, while hydrophobic molecules can intercalate into the membrane bilayer. The release kinetics of the payload may be difficult to fine tune with liposomes. Various both natural and synthetic polymers have been used for tNP manufacturing, including polylactic acid (PLA), poly(lactic-co-glycolic acid) (PLGA), polystyrene, acetylated dextran, poly-L-lysine, polyacrylamide, and chitosan. The use of biodegradable polymers is preferred for safety. Biodegradable PLGA/PLA polymers have an excellent safety profile and have been used in various approved drugs and medical devices. PLGA/PLA tNPs are formulated by an evaporation emulsion method. Unlike liposomes, PLA/ PLGA nanoparticles are solid particles in which the payload is embedded within the matrix. Hydrophobic molecules, such as rapamycin, dexamethasone, and vitamin $\mathrm{D} 3$, can be dissolved 


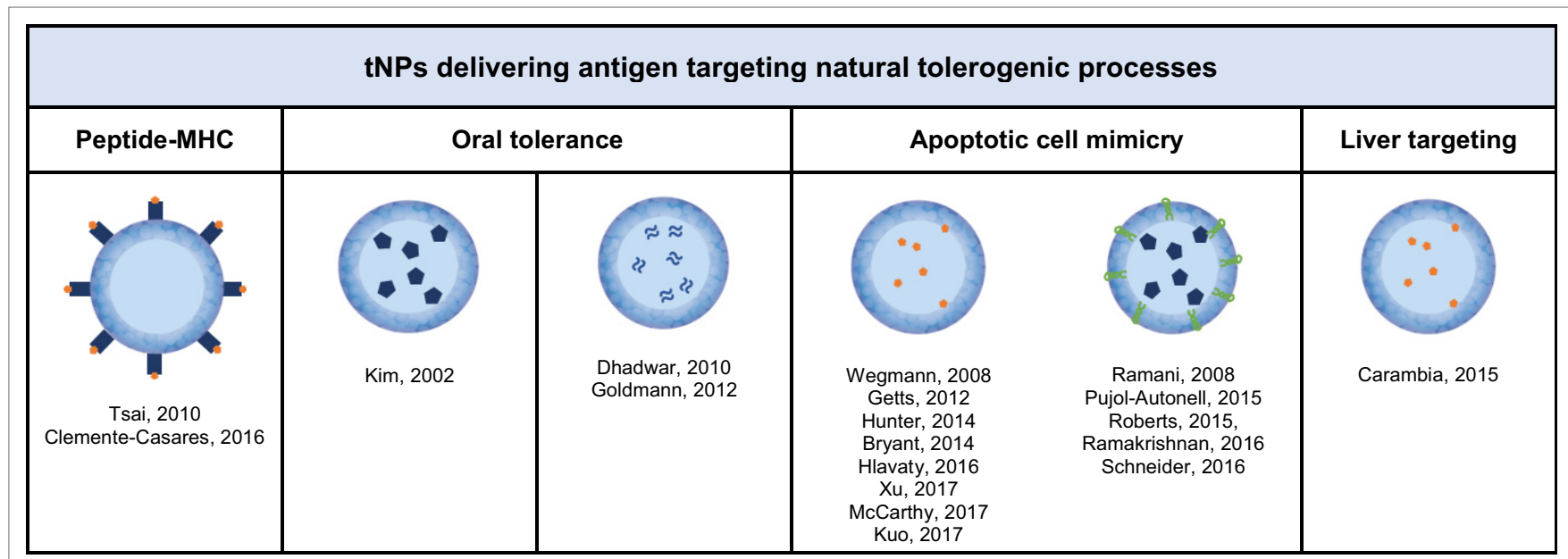

\begin{tabular}{|c|c|c|}
\hline \multicolumn{3}{|c|}{ tNPs delivering antigen and targeting tolerogenic receptors } \\
\hline Natural free ligands & $\begin{array}{c}\text { Protein antigen and } \\
\text { CD22 ligand }\end{array}$ & $\begin{array}{c}\text { Peptide-MHC and } \\
\text { Anti-Fas mAb agonist }\end{array}$ \\
\hline $\begin{array}{c}\text { Cappellano, 2014 } \\
\text { Yeste, 2016 }\end{array}$ & Lewis, 2015 \\
Cho, 2017 & Duong, 2010 \\
\hline
\end{tabular}

\begin{tabular}{|l|c|c|c|}
\hline \multicolumn{2}{|c|}{ tNPs with pharmacological inhibitors and antigen } & Hybrid tNPs \\
\hline Peptide antigen & Protein antigen & Free admixed protein antigen \\
\hline $\begin{array}{c}\text { Maldonado, 2015 } \\
\text { Kishimoto, 2016 } \\
\text { Tostanoski, 2016 }\end{array}$ & $\begin{array}{c}\text { Maldonini, 2009, 2015 } \\
\text { Kishimoto, 2016 }\end{array}$ & $\begin{array}{c}\text { Khang, 2016 } \\
\text { Lim, 2017 } \\
\text { Mazor, 2017 } \\
\text { Meliani, 2016 } \\
\text { Sands, 2017 }\end{array}$ & Kang, 2017 \\
\hline
\end{tabular}

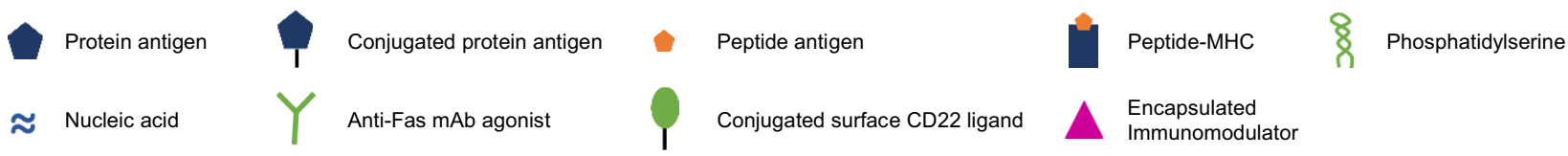

FIGURE 2 | Different types of tolerogenic nanoparticles according to their content and mechanism of action.

together with the polymer in a solvent and then emulsified with an aqueous phase-containing surfactants such as polyvinyl alcohol and pluronic $(57,59)$. Proteins and hydrophilic molecules can be incorporated through a double emulsion process (78). The release rate of the payload can be fine tuned by altering the glycolic acid to lactic acid ratio in PLGA, by changing the size of the polymer, and the use of excipients. The release rate can be further modified by conjugating molecules to the polymers which enables self-assembly of nanoparticles with the target molecules displayed on the surface or embedded within the matrix of the particles, as desired (79). The high shear process used to create nanoparticles may result in partial denaturation 
of proteins. However, if the protein payload is an antigen, then denaturation is not an issue, as the antigen is targeted for degradation by APCs. Functional proteins can be attached to the surface of nanoparticles to preserve protein structure and function.

Nanoparticle surface charge has a strong influence on the immune responses. Typically, cationic nanoparticles lead to pro-inflammatory responses while anionic surfaces display reduced immunogenicity and longer circulation times. Anionic PLGA tNPs with zeta potential values in range of -40 to $-70 \mathrm{mV}$ have been shown to target a specific population of macrophages in the spleen expressing the scavenger receptor MARCO $(48,49,51,80,81)$. In addition, many nanoparticle technologies use polyethylene glycol (PEG) to create a surface that is less prone to aggregation and opsonization by blood proteins, resulting in improved blood circulation properties $(82,83)$. Size can also affect circulation time and biodistribution. Particles smaller than $6 \mathrm{~nm}$ drain to the blood whereas particles larger than $9 \mathrm{~nm}$ tend to preferentially drain to lymphatics (84). Nanoparticles in the range of 20-100 $\mathrm{nm}$ have been shown to accumulate in the liver in liver sinusoidal endothelial cells (LSECs) or macrophages upon i.v. injection while after s.c. injections bigger particles have a tendency to become trapped in the extracellular environment and require active transport by phagocytes to reach the draining lymph nodes (85-88). Particles from 100 to $200 \mathrm{~nm}$ can traffic to both the spleen and liver when injected i.v. and circulate through the lymph after s.c. injections to be taken up by lymph sinus DCs that accumulate in draining lymph nodes $(88,89)$. Bigger particles from $200 \mathrm{~nm}$ to $5 \mu \mathrm{m}$ accumulate mostly in the spleen when injected i.v. and require active cellular transport to reach lymph nodes when injected s.c. $(50,66)$.

Ultimately, the choice of materials comes down to optimizing compatibility with the desired payload and activity. Within each class of material, there is a considerable range of options that can be used to optimize nanoparticles for specific payloads (e.g., immunomodulators) and activity (e.g., release rates). For example, there are different types of metals that can be used, a range of lipids that impart different properties to liposomes, and different types of polymer chemistries. Unfortunately, optimization is largely an empirical exercise. Therefore, it is important to have robust screens to optimize the features that are most desirable. While NF- $\mathrm{BB}$ inhibitors (65) and aryl hydrocarbon receptor (AHR) agonists $(63,64)$ have been demonstrated to be tolerogenic in liposomes and on gold particles, respectively, in our hands, these immunomodulators were not active in pilot PLGA nanoparticle formulations. It is possible that further optimization would be required to create similarly active particles with PLGA. However, certain nanoparticle materials may naturally lend themselves to be more compatible with certain types of immunomodulators.

If more than one payload is needed (e.g., antigen and immunomodulator), it also important to optimize the ratio of these two components. This can be difficult as one component may affect the encapsulation efficiency of the second component, thus it may be difficult to create a series of particles in which the load of the first component is held constant while varying the load of the second component. One strategy to work around this issue is to encapsulate the two components into separate nanoparticle formulations and admix different ratios of the two particles (66). This strategy is effective if the biodistribution of the two particles is sufficiently similar. Since a therapeutic dose of nanoparticles may involve the injection of billions of nanoparticles, APCs will endocytose hundreds of nanoparticles. However, one must keep in mind that B cells specific for the target antigen may selectively take up nanoparticles containing antigen. Once an optimal ratio is determined, then a single particle formulation containing both components in the appropriate ratio can be created and tested. There is, however, a risk that the optimal ratio for mice may be different in humans. Thus, it is worth considering to develop a two particle formulation for initial human clinical trials, so that different ratios can be evaluated.

\section{TOLEROGENIC NPS THAT PROVIDE ANTIGEN ALONE TO HARNESS NATURAL TOLEROGENIC PROCESSES OR ENVIRONMENTS}

Immune tolerance is the homeostatic, default pathway for antigen presented in the absence of costimulation in steady-state, non-inflammatory environments $(14,20,90)$. The immune system has evolved to distinguish between cells that undergo natural cell death, or apoptosis, versus necrotic cell death due to injury or infection. There are natural tolerogenic processes that not only maintain tolerance to self-antigens but also enable induction and maintenance of tolerance to innocuous food antigens and commensal bacterial antigens. Providing antigen in the context of these natural tolerogenic processes and environments is one strategy to induce antigen-specific tolerance.

\section{Peptide Antigens Presented on MHC-Bearing tNPs}

$\mathrm{T}$ cells recognize antigenic peptides presented in the context of major histocompatibility complex (MHC) class I (CD8 T cells) or MHC class II (CD4 T cells) and require a costimulatory second signal for activation of effector $\mathrm{T}$ cells. In the absence of costimulation, $\mathrm{T}$ cells become anergic, undergo apoptosis or differentiate into regulatory $\mathrm{T}$ cells $(12,13)$. Santamaria and colleagues created "synthetic APCs" by coating iron oxide nanoparticles with specific peptide-major histocompatibility class 1 complexes (pMHC-CLI). These tNPs present antigen in the absence of costimulatory molecules resulting in suppression of autoreactive $\mathrm{CD} 8+\mathrm{T}$ cells and their conversion to a regulatory, anergic phenotype that controlled pathogenic responses by a mechanism dependent on IFN $\gamma$ secretion, indoleamine 2,3-dioxygenase, and perforin expression (41). Importantly, this tolerance was antigen specific and dominant as transfer of CD8+ T cells from treated mice into a naïve prediabetic NOD animal conferred protection from development of type 1 diabetes (T1D).

This approach has also been extended to MHC class II molecules loaded with disease-relevant peptides (pMHC-CLII). These tNPs were efficacious in animal models of T1D, experimental autoimmune encephalomyelitis (EAE) and arthritis, but they worked through a different mechanism than pMHC-CLI-loaded 
tNPs (40). Treatment with pMHC-CLII-presenting tNPs led to the differentiation of IL-10-producing Tr1 regulatory cells and regulatory $B$ cells that were capable of transferring tolerance to untreated animals, even if the cells were antigen-experienced, suggesting that this approach could lead to reversal of memory responses.

While this approach is elegant, one of the hurdles for clinical development is the identification and validation of the relevant MHC alleles and peptides in the diverse human population. T1D and celiac disease may be the most amenable diseases for this approach, as there are strong disease associations with MHC-DQ/ DR alleles. Other diseases may require GMP manufacturing of multiple tNPs bearing different MHC alleles to treat a heterogenous population.

\section{Harnessing Oral Tolerance}

Delivery of antigen through the oral route has been shown to be tolerogenic, presumably through a mechanism that is similar to the tolerogenic response observed in all healthy individuals to dietary and gut flora antigens. However, current approaches to induce tolerance orally require chronic and frequent treatments (91). Kim et al. were among the first to load nanoparticles with antigen alone in the context of a model of collagen-induced arthritis (CIA). The authors showed that PLGA particles loaded with type II collagen (CII) provided orally 14 days before immunization with CII prevented CIA, antigen-induced $\mathrm{T}$ cell proliferation, anti-CIIA antibodies in a dose-dependent manner. The Peyer's patches of treated animals had an increased TGF $\beta / \mathrm{TNF} \alpha$ ratio, suggesting an active anti-inflammatory program in response to the antigen (43). Dhadwar et al. showed that repeated weekly administrations of chitosan nanoparticles containing DNA encoding coagulation factor VIII (FVIII) provides sustainable FVIII activity in hemophilia A mice while avoiding the induction of inhibitory and non-neutralizing anti-FVIII antibodies (44). Goldmann et al. investigated a similar approach with ovalbumin (OVA)encoding DNA encapsulated in chitosan tNP and showed suppressed OVA-specific delayed-type hypersensitivity (DTH) and anti-OVA antibody responses and transferable tolerance mediated by CD4+ CD25+ T cells (45).

While oral tolerance has been shown to be effective in mice, human clinical trials of oral tolerance have been largely disappointing. It is also not clear if non-viral oral delivery of DNA-bearing nanoparticles in humans would result in sufficient and sustained levels of antigen expression to induce immune tolerance.

\section{Harnessing Apoptotic Cell Death}

Cells that undergo necrotic cell death, due to tissue damage or infection, induce an immunogenic response, while cells that undergo apoptosis, or programmed cell death, generally induce a tolerogenic response $(92,93)$. Coupling antigens to spleen cells through ethylenecarbodiimide (ECDI) fixation has been shown to induce their apoptosis and treatments with these dead cell-peptide conjugates confers tolerance to the antigen in many preclinical models. This approach has been used to treat various diseases, including animal models of EAE and T1D $(94,95)$. A similar strategy has been employed to target disease-relevant antigens to erythrocytes in vivo. Erythrocyte cell death led to immunologic tolerance to the bound antigen and protection in a model of autoimmune T1D (96). The adaptation of this approach to nanoparticles has involved delivery of peptide antigens coupled to dendrimers and to polystyrene and PLGA carriers. Treatment with pathogenic peptides conjugated to dendrimers protected animals from developing EAE with a concomitant reduction of effector T cells in the CNS (46). A similar approach using $500 \mathrm{~nm}$ carboxylated polystyrene beads with a mixture of immunodominant $\mathrm{HLA}-\mathrm{A}^{\star}$ 02:01-restricted epitopes was used to treat HHD II mice ( $\beta 2 \mathrm{mKO} / \mathrm{HLA}-\mathrm{A}^{\star} 0201$ transgenic mouse) and inhibit diabetogenic human cytotoxic $\mathrm{T}$ cell (CTL) responses in a Treg-dependent manner (52). Negatively charged 500 nm PLGA nanoparticles delivered intravenously target splenic macrophages that express the scavenger receptor MARCO (47). This approach has shown to be efficacious in preventing and treating autoimmune processes in relapsing-remitting EAE and T1D and in preventing graft rejection in bone marrow transplantation and allogenic pancreatic islet transplantation $(47-49,51,80,81$, $94,95)$. Tolerance induction was demonstrated by challenging treated animals with the antigen after disease resolution or the prolonged survival of grafts $(47,48,51)$ and the elimination of pathogenic effector $\mathrm{T}$ cells by induction of apoptosis and anergy $(94,95)$. The precise mechanism for the induction of tolerance by negatively charged tNPs remains to be elucidated. Recently Kuo et al. described that pro-inflammatory transcription factors $\mathrm{NF}-\kappa \mathrm{B}$ and STAT1 are triggered in macrophages and DCs when incubated with this type of nanoparticle. However, the cells had a decreased capacity for presenting antigen, displayed a restricted costimulatory-molecule phenotype with low expression of CD86, CD80, and CD40 and showed upregulation of STAT3, IL-10, and sustained PD-L1 expression, a profile associated with antiinflammatory functions (80). Interestingly this phenotype was observed in both macrophages and DCs, while tolerance induced by negatively charged tNPs has been described to be dependent on MARCO+ macrophages only (47). It is not clear how negatively charged nanoparticles mimic apoptotic cells, or whether they recapitulate the full tolerogenic phenotype of apoptotic cells. It appears that the use of charged nanoparticles to induce tolerance works best with peptide antigens, while ECDI-fixed splenocytes and erythrocytes undergoing cell death can confer tolerance to either peptide or protein antigens. It is possible that the inherently immunogenic properties of protein antigen displayed in a multimeric fashion on NPs cannot be overcome with this approach. Interestingly, the survival of allogenic pancreatic islets graft in mice treated with poly(lactide-co-glycolide) particles containing alloantigen was synergistic with low dose free rapamycin, suggesting that this approach could be substantially improved by the addition of an immunosuppressant (49).

Another approach to mimic apoptotic cells is to cloak liposomes with Phosphatidylserine (PS). PS is a phospholipid forming part of the cell membrane that is translocated from the cytosolic (inner) to the extracellular (outer) membrane of cells undergoing apoptosis. Macrophages express various PS-specific scavenger receptors, such as Tyro3, Axl, and Mertk (collectively referred to as TAM receptors), TIM-3 and SCARF-1 that trigger the phagocytosis of dying cells and promote induction of a 
tolerogenic phenotype, such as the increase in IL-10 and TGF $\beta$ secretion, and a decrease in NF- $\mathrm{BB}$ signaling and TNF $\alpha$, IL- $1 \beta$, and IL-12 secretion (97). Encapsulating coagulation FVIII in PS-bearing liposomes was effective to prevent the formation of inhibitory anti-FVIII antibodies in hemophilia A animals even when animals were challenged with FVIII alone $(53,57,98,99)$. A similar approach was demonstrated with alpha-glucosidase (GAA) in a mouse model of Pompe disease. Administration of GAA-containing PS liposomes provided therapeutically active enzyme while preventing the formation of inhibitory antibodies (56). In an autoimmune setting, PS liposomes loaded with disease-relevant peptides were protective in the NOD animal model of T1D (54) and PLGA nanoparticles displaying PS and containing peptide autoantigens (from myelin oligodendrocyte protein, $\mathrm{MOG}_{35-55}$ ) were also efficacious in an acute model of EAE (in B6 mice) (55).

\section{Harnessing the Tolerogenic Environment of the Liver}

The liver is considered a tolerogenic organ due to its unique function in filtering antigens from blood delivered from the gastrointestinal tract via the hepatic portal veins $(100,101)$. The liver is constantly bathed in food antigens and commensal bacterial products, "foreign" products to which immunological tolerance must be induced and maintained in healthy organisms. Carambia et al. (50) have shown that peptide-coupled poly(maleic anhydride-alt-1-octadecene)-coated nanoparticles injected i.v. protected mice in a model of EAE in a Treg-dependent manner. Microscopy studies showed selective uptake of these nanoparticles by LSECs.

\section{TOLEROGENIC NPS THAT PROVIDE ANTIGEN WHILE TARGETING TOLEROGENIC RECEPTORS}

One of the potential concerns about delivering nanoparticles containing only antigen is that in an inflammatory microenvironment, these tNPs could inadvertently provoke a stimulatory immune response and exacerbate an autoimmune condition. One strategy to mitigate this risk is to create tNPs that deliver antigen while simultaneously targeting tolerogenic receptors.

\section{Harnessing Cytokine Mediators of Immunological Tolerance}

One strategy is to create a tolerogenic environment by co-delivery of antigen with nanoparticle-encapsulated anti-inflammatory cytokines and soluble mediators. Encapsulated $\mathrm{MOG}_{35-55}$ and rIL-10 ameliorated the course of EAE induced with $\mathrm{MOG}_{35-55}$ in C57BL/6 mice (58). Furthermore, two groups developed a system of multiple microparticles with different functionalities engineered to be phagocytosed and release their cargo in the intracellular space or avoid phagocytosis and release anti-inflammatory cytokines in their environment. This dual system allowed for the release of antigen and vitamin D3 inside APCs and TGF $\beta$ and GM-CSF extracellularly. Although tolerance induction was not demonstrated, treatments with these particles showed the immunoregulatory capacity of encapsulated cytokines by preventing T1D in NOD animals (59) and EAE in $\mathrm{MOG}_{35-55}$-immunized animals (60) consistent with a general suppressed phenotype of CD4+ T cells and a tolerogenic phenotypes on APCs. A hurdle for clinical development is the requirement to produce one or more GMP cytokines.

\section{Harnessing AHR Agonists}

The AHR is a ligand-activated transcription factor that controls the differentiation of Foxp3+ and IL-10+ Tregs and Th17 cells. Quintana and colleagues have shown that an endogenous AHR ligand, 2-(1'H-indole-3'-carbonyl)-thiazole-4-carboxylic acid methyl ester (ITE), co-delivered with myelin peptide $\mathrm{MOG}_{35-55^{-}}$ loaded on gold nanoparticles promote the generation of Tregs in vitro and in vivo that were capable of transferring tolerance to naïve animals (63). This approach was also efficacious with protein antigen, as ITE and proinsulin-loaded tNPs suppressed autoimmune diabetes in NOD animals. Interestingly, treatment with these particles induced a Socs2-dependent itDC phenotype characterized the inhibition of NF- $\mathrm{KB}$ signaling, a decreased ability to active Teff cells and an increased differentiation of Foxp3+ Treg cells (64).

\section{Targeting the Fas Receptor to Kill Antigen-Specific Effector Cells}

The Fas receptor mediates programmed cell death. Shen et al. created artificial APCs with latex beads coated with pMHC-CLI complexes and a monoclonal antibody directed against Fas receptor, which caused the deletion of antigen-specific CTLs in an animal model of skin graft (42). A potential hurdle for clinical development is the cost of producing GMP manufactured monoclonal antibodies.

\section{Targeting B Cell-Specific Tolerance through CD22}

$B$ cells play a unique role in the immune system by serving as both APCs and antigen-specific effector cells. The BCR, a transmembrane splice variant of an antibody, can directly bind to its cognate antigen and trigger B cell activation. To prevent activation to autoantigens, B cells express inhibitory co-receptors, such as CD22, a member of the SIGLEC family of lectins that binds to sialic acid-bearing glycoproteins and glycolipids. Co-localization of CD22 with the BCR results in the recruitment of phosphatases that inhibit BCR signaling and result in B cell deletion. The Paulson group developed liposomal nanoparticles, called SIGLEC-engaging tolerance-inducing antigenic liposomes (STALs) displaying both antigen and CD22 glycan ligands on their surface that induce apoptosis in mouse and human B cells. Animals treated with STALs did not develop antibody responses to $\mathrm{T}$ cell-independent antigens, such as nitrophenol, or $\mathrm{T}$ celldependent protein antigens, such as coagulation FVIII, even after repeated immunogenic challenges $(61,62)$. It is notable that this approach is compatible with the use of protein antigens, as the inhibitory signal delivered by CD22 co-engagement is sufficient to override the inherent immunogenicity of a protein-bearing nanocarrier. One potential hurdle for clinical development is the difficulty and cost of synthesizing CD22 glycan ligands. 


\section{TOLEROGENIC NPS THAT HARNESS TOLEROGENIC PHARMACOLOGICAL AGENTS}

Recently, a number of researchers have investigated pharmacological agents capable of inducing tolerogenic DCs (102-104). The potential advantage of pharmacological mediators of tolerance is the potential ability to "lock-in" a tolerogenic phenotype even in the face of an inflammatory microenvironment. While autologous tolerogenic DCs induced ex vivo could be used therapeutically, such individualized cell therapy would be costly and difficult to scale. However, nanoparticles represent an ideal "off-the-shelf" vehicle to deliver a payload of both target antigen and tolerogenic drug to induce endogenous tolerogenic DCs in vivo. To date, pharmacological agents targeting at least two different signaling pathways have been used in tNPs to induce antigen-specific tolerance in vivo.

\section{NF-кB Inhibitors}

NF kappa B is a master regulator of a broad array of genes controlling inflammation and cell survival. Thomas and colleagues have demonstrated that co-delivery of antigen with various NF- $\kappa \mathrm{B}$ inhibitors, such as curcumin, quercetin, and Bay11-07082, in liposomes suppressed inflammatory arthritis in an antigenspecific manner (65). The liposomes accumulated in lymph nodes and spleen following i.v. injection and were taken up by $\mathrm{MHC}$ class II+ APCs resulting in inhibition of NF- $\kappa$ B activation. Mice treated with liposomes showed induction of Ag-specific Foxp3+ regulatory $\mathrm{T}$ cells, which conferred protection when adoptively transferred into naïve animals. Depletion of Tregs with antiCD25 antibodies abrogated the tolerogenic activity of the tNPs.

\section{mTOR Inhibitors}

Mammalian target of rapamycin is a conserved serine/threonine kinase that integrates environmental signals to regulate cell metabolism and survival. Rapamycin is a natural product derived from Streptomyces hygroscopicus, which binds to the FK506-binding protein to form a complex that acts as an allosteric inhibitor of the mTOR complex-1 pathway. Rapamycin was found to have potent immunosuppressive activity based on its ability to inhibit $\mathrm{T}$ cell proliferation and is approved for the prophylaxis of renal allograft rejection. Importantly rapamycin treatment has been shown to promote Treg expansion and differentiation $(27,105,106)$. In addition to its direct effects on $\mathrm{T}$ cells, Thomson and colleagues have demonstrated that in vitro treatment of DC induces a tolerogenic phenotype $(25,27)$.

We screened a large number of immunomodulators for compatibility with biodegradable PLA and PLGA nanoparticles and found that rapamycin-loaded nanoparticles showed potent tolerogenic activity in vivo. We and others have shown that tNPs containing rapamycin induced durable antigenspecific immune tolerance when coadministered with various encapsulated or free protein and peptide antigens. These tNPs were selectively taken up by APCs in lymphoid organs (66) and demonstrated efficacy when coadministered with antigen by i.v., s.c., or direct intranodal injection $(66,69)$. The tNPs were shown to generated itDCs and Foxp3+CD4+ $\mathrm{T}$ cells in vivo and inhibit CD4+ and CD8+ $\mathrm{T}$ cell effector cell activation $(30,66)$. Moreover, weekly doses of tNPs encapsulating rapamycin, but not daily doses of free rapamycin, were effective in inducing immune tolerance (30). Indeed, a single dose of tNPs co-encapsulating rapamycin and antigen inhibited antigenspecific $\mathrm{T}$ cell expansion while increasing the proportion of Foxp3+ T cells, while the equivalent doses of encapsulated antigen with free rapamycin had the opposite effect (66). This difference may be attributed to the selective targeting of tNPs to APCs in the draining lymph nodes. Importantly, immune tolerance induced by tNPs encapsulating rapamycin was effective even when coadministered with a potent TLR7/8 agonist and was maintained in animals challenged with antigen coadministered with TLR agonists or emulsified in complete Freund's adjuvant. Tolerogenic NPs containing co-encapsulated antigen and rapamycin were effective in preventing $\mathrm{T}$ cellmediated pathologies such as DTH reactions and EAE. In addition, therapeutic treatment at the peak of disease was effective in reversing paralysis in a model of $\operatorname{EAE}(66,69)$. Tolerance induced by tNPs encapsulating rapamycin could be transferred to naïve animals (107).

In addition, rapamycin-containing tNPs inhibited $B$ cell activation and differentiation into effector cells, germinal center formation and antibody production. These rapamycin-containing $\mathrm{tNPs}$ were effective in preventing IgE-mediated anaphylaxis in models of allergy, IgG-mediated anaphylaxis associated with repeated intravenous challenges with antigen, and the formation of anti-drug antibodies (ADAs) to a wide range of biologic drugs. Coadministration of tNPs containing rapamycin with free biologic drugs was effective in preventing ADAs against coagulation FVIII (Advate ${ }^{\circledR}$ ) in a model of hemophilia A (66, 67); human TNF $\alpha$-blocking antibody adalimumab (Humira ${ }^{\circledR}$ ) in a model of inflammatory arthritis (30), acid- $\alpha$-glucosidase (Lumizyme $^{\circledR}$ ) in a model of Pompe disease (70), recombinant immunotoxin in a model of mesothelioma (71), adenoassociated virus gene therapy vectors (68) and pegylated uricase (pegsiticase) in uricase-deficient mice and non-human primates (30). Currently the combination of tNP-rapamycin and pegsiticase (SEL-212) is in Phase 2 clinical trials (NCT02959918) in patients with symptomatic gout and hyperuricemia (see Human Translation).

\section{HYBRID tNPs}

Strategies that employ tNPs that harness natural tolerogenic mechanisms and those that incorporate a pharmacological mediator of tolerance may have synergistic effects. Recently Paulson and colleagues added low doses of rapamycin to their STALs liposomes that present antigen in context with a CD22 ligand (108). While CD22 ligand co-localized with antigen would directly inhibit antigen-specific $B$ cell activation, it would not prevent $\mathrm{T}$ cell activation by DCs and macrophages that also take up the STALs particles. Preliminary data indicate that the addition of low dose rapamycin enhanced the tolerogenic response, presumably by mitigating antigen-specific $\mathrm{T}$ cell activation. 


\section{HUMAN TRANSLATION}

Currently, the treatment of autoimmune diseases requires lifelong use of general immunosuppressants or immunomodulators that may target-specific pathways (e.g., TNF- $\alpha$ ) but are not antigen-specific. A long-standing goal for immunotherapy is the development of antigen-specific therapies that leave the rest of the immune system intact and that can arrest or even reverse disease pathology. Clinical translation of other (non-nanoparticlebased) strategies to induce antigen-specific tolerance induction has been challenging and largely disappointing. The immune system is a complex network of cells, organs, and soluble factors that must integrate multiple environmental cues to determine how to respond to a given antigen. Nanoparticles are ideal vehicles to mediate antigen-specific immune modulation, as they can be engineered to provide multiple coordinated signals to shape the immune response. For example, nanoparticles have been developed for stimulatory vaccines by incorporating antigen and TLR agonists or other pro-inflammatory adjuvants. Creating tolerogenic or "inverse" vaccines using nanoparticles that harness natural tolerogenic mechanisms or employ tolerogenic pharmacological agents is an attractive concept. The preclinical data demonstrating induction of antigen-specific tolerance using a wide variety of nanoparticle materials and strategies is compelling. However, clinical translation remains a key hurdle for the field.

It is worth considering why clinical translation in immune tolerance has been so vexing. There are several factors to consider. (1) Animals models of autoimmunity are poorly predictive of human disease. In addition to obvious differences in the immune system, genetic diversity, lifespan, and environmental factors between humans and laboratory mice, there are a number of limitations of mouse models specific to autoimmune diseases. For example, many mouse models of autoimmunity are homogenous acute models that often, as in the case of EAE, use a single immunization with a single antigen to trigger pathology while most autoimmune disorders in humans are chronic and heterogenous diseases that develop over many years. (2) Antigen uncertainty. For many human autoimmune diseases, there are usually multiple candidate antigens with epitope spreading that occurs with disease progression. Moreover, the pathogenic antigens may vary from patient to patient. This antigen selection risk is compounded for peptide-based immunotherapies, as dominant peptide epitopes may vary widely among different patients due to heterogeneity in MHC alleles and $\mathrm{T}$ cell receptor repertoire. (3) Requirement for therapeutic activity in established disease. Modifying a memory immune response is considerably more challenging than affecting a naïve response. For example, there

\section{REFERENCES}

1. Josefowicz SZ, Lu LF, Rudensky AY. Regulatory T cells: mechanisms of differentiation and function. Annu Rev Immunol (2012) 30:531-64. doi:10.1146/ annurev.immunol.25.022106.141623

2. Danke NA, Koelle DM, Yee C, Beheray S, Kwok WW. Autoreactive T cells in healthy individuals. J Immunol (2004) 172(10):5967-72. doi:10.4049/ jimmunol.172.10.5967 are many highly effective prophylactic vaccines dating back to 1796 with Jenner's small pox vaccine; however, there is only one approved therapeutic vaccine, Provenge ${ }^{\circledR}$, a modestly effective DC vaccine for prostate cancer. In mouse models of autoimmune disease, it is difficult to study true therapeutic activity in the setting of well-established disease involving memory $\mathrm{T}$ cell populations. Thus, it is challenging to assess whether the failure of clinical translation of immune tolerance strategies is due to non-predictive animal models, incorrect antigen selection, or short-comings of the therapeutic strategy.

To mitigate some of these challenges in assessing the clinical efficacy of rapamycin-containing tNPs, we have chosen to focus on the mitigation of ADAs to biologic therapies (30). ADAs are a common cause for biologic treatment failure and hypersensitivity reactions. Using this strategy confers several significant advantages as (1) the animal models are simple immunization models, and the clinical proof-of-concept is relatively straightforward with a well-established and easily measured biomarker readout (ADA titers), (2) the antigen is unequivocally known, as it is the biologic drug itself, and (3) the tolerizing therapy can be administered prophylactically, as it is known when the patient receives the drug. Our lead clinical program, SEL-212, is the first immune tolerizing nanoparticle technology to reach the clinic. SEL-212 is a combination therapy consisting of rapamycin-containing tNPs coadministered with pegylated uricase, a uric acid metabolizing enzyme, for the treatment of severe, chronic gout. Preclinical studies demonstrated the ability of these tNPs to prevent the formation of ADAs in uricase-deficient hyperuricemic mice enabling the enzyme to achieve sustained control of serum uric acid levels (30). Similar effects on ADA prevention were obtained in rats and non-human primates (30). A single ascending dose Phase 1 clinical trial of SEL-212 (NCT02648269) in patients with hyperuricemia showed that the pegylated uricase is highly immunogenic in humans even after a single dose of enzyme. The addition of tNPs showed a dose-dependent inhibition of anti-uricase antibody formation resulting in sustained reduction of serum uric acid levels (72). An ongoing Phase 2 study (NCT02959918) will assess the ability of multiple doses of SEL-212 to inhibit the formation of ADAs with in patients with symptomatic gout and hyperuricemia.

\section{AUTHOR CONTRIBUTIONS}

RM and TK wrote and edited this review.

\section{FUNDING}

This work self-funded by Selecta Biosciences Inc.

3. Herzog S, Jumaa H. Self-recognition and clonal selection: autoreactivity drives the generation of B cells. Curr Opin Immunol (2012) 24(2):166-72. doi:10.1016/j.coi.2012.02.004

4. Kono H, Rock KL. How dying cells alert the immune system to danger Nat Rev Immunol (2008) 8(4):279-89. doi:10.1038/nri2215

5. Kaczmarek A, Vandenabeele P, Krysko DV. Necroptosis: the release of damage-associated molecular patterns and its physiological relevance. Immunity (2013) 38(2):209-23. doi:10.1016/j.immuni.2013.02.003 
6. O’Neill LA, Pearce EJ. Immunometabolism governs dendritic cell and macrophage function. JExp Med (2016) 213(1):15-23. doi:10.1084/ jem. 20151570

7. Murtaugh MP, Foss DL. Inflammatory cytokines and antigen presenting cell activation. Vet Immunol Immunopathol (2002) 87(3-4):109-21. doi:10.1016/S0165-2427(02)00042-9

8. Brunekreeft KL, Strohm C, Gooden MJ, Rybczynska AA, Nijman HW, Grigoleit GU, et al. Targeted delivery of CD40L promotes restricted activation of antigen-presenting cells and induction of cancer cell death. Mol Cancer (2014) 13:85. doi:10.1186/1476-4598-13-85

9. Tak PP, Firestein GS. NF-kappaB: a key role in inflammatory diseases. J Clin Invest (2001) 107(1):7-11. doi:10.1172/JCI11830

10. Dalod M, Chelbi R, Malissen B, Lawrence T. Dendritic cell maturation: functional specialization through signaling specificity and transcriptional programming. EMBO J (2014) 33(10):1104-16. doi:10.1002/embj.201488027

11. Linke M, Fritsch SD, Sukhbaatar N, Hengstschlager M, Weichhart T. mTORC1 and mTORC2 as regulators of cell metabolism in immunity. FEBS Lett (2017) 591(19):3089-103. doi:10.1002/1873-3468.12711

12. Adams AB, Ford ML, Larsen CP. Costimulation blockade in autoimmunity and transplantation: the CD28 pathway. J Immunol (2016) 197(6):2045-50. doi:10.4049/jimmunol.1601135

13. Esensten JH, Helou YA, Chopra G, Weiss A, Bluestone JA. CD28 costimulation: from mechanism to therapy. Immunity (2016) 44(5):973-88. doi:10.1016/j.immuni.2016.04.020

14. Maldonado RA, von Andrian UH. How tolerogenic dendritic cells induce regulatory T cells. Adv Immunol (2010) 108:111-65. doi:10.1016/B978-012-380995-7.00004-5

15. Mauri C, Bosma A. Immune regulatory function of B cells. Annu Rev Immunol (2012) 30(1):221-41. doi:10.1146/annurev-immunol-020711-074934

16. Talmadge JE, Gabrilovich DI. History of myeloid-derived suppressor cells. Nat Rev Cancer (2013) 13(10):739-52. doi:10.1038/nrc3581

17. Audiger C, Rahman MJ, Yun TJ, Tarbell KV, Lesage S. The importance of dendritic cells in maintaining immune tolerance. J Immunol (2017) 198(6):2223-31. doi:10.4049/jimmunol.1601629

18. Ezzelarab M, Thomson AW. Tolerogenic dendritic cells and their role in transplantation. Semin Immunol (2011) 23(4):252-63. doi:10.1016/j.smim. 2011.06.007

19. Li H, Shi B. Tolerogenic dendritic cells and their applications in transplantation. Cell Mol Immunol (2015) 12(1):24-30. doi:10.1038/cmi.2014.52

20. Osorio F, Fuentes C, Lopez MN, Salazar-Onfray F, Gonzalez FE. Role of dendritic cells in the induction of lymphocyte tolerance. Front Immunol (2015) 6:535. doi:10.3389/fimmu.2015.00535

21. Takenaka MC, Quintana FJ. Tolerogenic dendritic cells. Semin Immunopathol (2017) 39(2):113-20. doi:10.1007/s00281-016-0587-8

22. Walton EL. Make immunological peace not war: potential applications of tolerogenic dendritic cells. Biomed J (2017) 40(2):77-9. doi:10.1016/j. bj.2017.04.001

23. Ardouin L, Luche H, Chelbi R, Carpentier S, Shawket A, Montanana Sanchis F, et al. Broad and largely concordant molecular changes characterize tolerogenic and immunogenic dendritic cell maturation in thymus and periphery. Immunity (2016) 45(2):305-18. doi:10.1016/j. immuni.2016.07.019

24. Vander Lugt B, Riddell J, Khan AA, Hackney JA, Lesch J, DeVoss J, et al. Transcriptional determinants of tolerogenic and immunogenic states during dendritic cell maturation. JCell Biol (2017) 216(3):779-92. doi:10.1083/ jcb.201512012

25. Turnquist HR, Raimondi G, Zahorchak AF, Fischer RT, Wang Z, Thomson AW. Rapamycin-conditioned dendritic cells are poor stimulators of allogeneic CD4+ T cells, but enrich for antigen-specific Foxp $3+T$ regulatory cells and promote organ transplant tolerance. J Immunol (2007) 178(11):7018-31. doi:10.4049/jimmunol.178.11.7018

26. Haddadi A, Elamanchili P, Lavasanifar A, Das S, Shapiro J, Samuel J. Delivery of rapamycin by PLGA nanoparticles enhances its suppressive activity on dendritic cells. JBiomed Mater Res A (2008) 84(4):885-98. doi:10.1002/jbm.a.31373

27. Fischer R, Turnquist HR, Taner T, Thomson AW. Use of rapamycin in the induction of tolerogenic dendritic cells. Handb Exp Pharmacol (2009) 18:215-32. doi:10.1007/978-3-540-71029-5_10
28. Pothoven KL, Kheradmand T, Yang Q, Houlihan JL, Zhang H, Degutes M, et al. Rapamycin-conditioned donor dendritic cells differentiate CD4CD25Foxp3 $\mathrm{T}$ cells in vitro with TGF-beta1 for islet transplantation. Am J Transplant (2010) 10(8):1774-84. doi:10.1111/j.1600-6143.2010.03199.x

29. Rosborough BR, Raich-Regue D, Matta BM, Lee K, Gan B, DePinho RA, et al. Murine dendritic cell rapamycin-resistant and rictor-independent mTOR controls IL-10, B7-H1, and regulatory T-cell induction. Blood (2013) 121(18):3619-30. doi:10.1182/blood-2012-08-448290

30. Kishimoto TK, Ferrari JD, LaMothe RA, Kolte PN, Griset AP, O'Neil C, et al. Improving the efficacy and safety of biologic drugs with tolerogenic nanoparticles. Nat Nanotechnol (2016) 11(10):890-9. doi:10.1038/nnano. 2016.135

31. Metcalfe SM, Fahmy TM. Targeted nanotherapy for induction of therapeutic immune responses. Trends Mol Med (2012) 18(2):72-80. doi:10.1016/j. molmed.2011.11.002

32. Smith DM, Simon JK, Baker JR Jr. Applications of nanotechnology for immunology. Nat Rev Immunol (2013) 13(8):592-605. doi:10.1038/nri3488

33. Getts DR, Shea LD, Miller SD, King NJ. Harnessing nanoparticles for immune modulation. Trends Immunol (2015) 36(7):419-27. doi:10.1016/j. it.2015.05.007

34. Gharagozloo M, Majewski S, Foldvari M. Therapeutic applications of nanomedicine in autoimmune diseases: from immunosuppression to tolerance induction. Nanomedicine (2015) 11(4):1003-18. doi:10.1016/j.nano. 2014.12.003

35. Serra P, Santamaria P. Nanoparticle-based autoimmune disease therapy. Clin Immunol (2015) 160(1):3-13. doi:10.1016/j.clim.2015.02.003

36. Irvine DJ, Swartz MA, Szeto GL. Engineering synthetic vaccines using cues from natural immunity. Nat Mater (2013) 12(11):978-90. doi:10.1038/ nmat 3775

37. Irvine DJ, Hanson MC, Rakhra K, Tokatlian T. Synthetic nanoparticles for vaccines and immunotherapy. Chem Rev (2015) 115(19):11109-46. doi:10.1021/acs.chemrev.5b00109

38. Gomes AC, Mohsen M, Bachmann MF. Harnessing nanoparticles for immunomodulation and vaccines. Vaccines (Basel) (2017) 5(1). doi:10.3390/ vaccines5010006

39. Tostanoski LH, Jewell CM. Engineering self-assembled materials to study and direct immune function. Adv Drug Deliv Rev (2017) 114:60-78. doi:10.1016/j.addr.2017.03.005

40. Clemente-Casares X, Blanco J, Ambalavanan P, Yamanouchi J, Singha S, Fandos C, et al. Expanding antigen-specific regulatory networks to treat autoimmunity. Nature (2016) 530(7591):434-40. doi:10.1038/nature16962

41. Tsai S, Shameli A, Yamanouchi J, Clemente-Casares X, Wang J, Serra P, et al. Reversal of autoimmunity by boosting memory-like autoregulatory T cells. Immunity (2010) 32(4):568-80. doi:10.1016/j.immuni.2010.03.015

42. Shen C, He Y, Cheng K, Zhang D, Miao S, Zhang A, et al. Killer artificial antigen-presenting cells deplete alloantigen-specific $\mathrm{T}$ cells in a murine model of alloskin transplantation. Immunol Lett (2011) 138(2):144-55. doi:10.1016/j.imlet.2011.04.002

43. Kim WU, Lee WK, Ryoo JW, Kim SH, Kim J, Youn J, et al. Suppression of collagen-induced arthritis by single administration of poly(lactic-co-glycolic acid) nanoparticles entrapping type II collagen: a novel treatment strategy for induction of oral tolerance. Arthritis Rheum (2002) 46(4):1109-20. doi:10.1002/art.10198

44. Dhadwar SS, Kiernan J, Wen J, Hortelano G. Repeated oral administration of chitosan/DNA nanoparticles delivers functional FVIII with the absence of antibodies in hemophilia A mice. J Thromb Haemost (2010) 8(12):2743-50. doi:10.1111/j.1538-7836.2010.04116.x

45. Goldmann K, Ensminger SM, Spriewald BM. Oral gene application using chitosan-DNA nanoparticles induces transferable tolerance. Clin Vaccine Immunol (2012) 19(11):1758-64. doi:10.1128/CVI.00186-12

46. Wegmann KW, Wagner CR, Whitham RH, Hinrichs DJ. Synthetic peptide dendrimers block the development and expression of experimental allergic encephalomyelitis. J Immunol (2008) 181(5):3301-9. doi:10.4049/ jimmunol.181.5.3301

47. Getts DR, Martin AJ, McCarthy DP, Terry RL, Hunter ZN, Yap WT, et al. Microparticles bearing encephalitogenic peptides induce T-cell tolerance and ameliorate experimental autoimmune encephalomyelitis. Nat Biotechnol (2012) 30(12):1217-24. doi:10.1038/nbt.2434 
48. Hunter Z, McCarthy DP, Yap WT, Harp CT, Getts DR, Shea LD, et al. A biodegradable nanoparticle platform for the induction of antigen-specific immune tolerance for treatment of autoimmune disease. ACS Nano (2014) 8(3):2148-60. doi:10.1021/nn405033r

49. Bryant J, Hlavaty KA, Zhang X, Yap WT, Zhang L, Shea LD, et al. Nanoparticle delivery of donor antigens for transplant tolerance in allogeneic islet transplantation. Biomaterials (2014) 35(31):8887-94. doi:10.1016/j. biomaterials.2014.06.044

50. Carambia A, Freund B, Schwinge D, Bruns OT, Salmen SC, Ittrich H, et al. Nanoparticle-based autoantigen delivery to Treg-inducing liver sinusoidal endothelial cells enables control of autoimmunity in mice. J Hepatol (2015) 62(6):1349-56. doi:10.1016/j.jhep.2015.01.006

51. Hlavaty KA, McCarthy DP, Saito E, Yap WT, Miller SD, Shea LD. Tolerance induction using nanoparticles bearing HY peptides in bone marrow transplantation. Biomaterials (2016) 76:1-10. doi:10.1016/j.biomaterials.2015. 10.041

52. Xu X, Bian L, Shen M, Li X, Zhu J, Chen S, et al. Multipeptide-coupled nanoparticles induce tolerance in 'humanised' HLA-transgenic mice and inhibit diabetogenic CD8+ T cell responses in type 1 diabetes. Diabetologia (2017) 60(12):2418-31. doi:10.1007/s00125-017-4419-8

53. Ramani K, Miclea RD, Purohit VS, Mager DE, Straubinger RM, Balu-Iyer SV. Phosphatidylserine containing liposomes reduce immunogenicity of recombinant human factor VIII (rFVIII) in a murine model of hemophilia A. J Pharm Sci (2008) 97(4):1386-98. doi:10.1002/jps.21102

54. Pujol-Autonell I, Serracant-Prat A, Cano-Sarabia M, Ampudia RM, Rodriguez-Fernandez S, Sanchez A, et al. Use of autoantigen-loaded phosphatidylserine-liposomes to arrest autoimmunity in type 1 diabetes. PLoS One (2015) 10(6):e0127057. doi:10.1371/journal.pone.0127057

55. Roberts RA, Eitas TK, Byrne JD, Johnson BM, Short PJ, McKinnon KP, et al. Towards programming immune tolerance through geometric manipulation of phosphatidylserine. Biomaterials (2015) 72:1-10. doi:10.1016/j. biomaterials.2015.08.040

56. Schneider JL, Balu-Iyer SV. Phosphatidylserine converts immunogenic recombinant human acid alpha-glucosidase to a tolerogenic form in a mouse model of Pompe disease. J Pharm Sci (2016) 105(10):3097-104. doi:10.1016/j. xphs.2016.06.018

57. Ramakrishnan R, Balu-Iyer SV. Effect of biophysical properties of phosphatidylserine particle on immune tolerance induction toward factor VIII in a hemophilia A mouse model. JPharm Sci (2016) 105(10):3039-45. doi:10.1016/j.xphs.2016.06.008

58. Cappellano G, Woldetsadik AD, Orilieri E, Shivakumar Y, Rizzi M, Carniato F, et al. Subcutaneous inverse vaccination with PLGA particles loaded with a MOG peptide and IL-10 decreases the severity of experimental autoimmune encephalomyelitis. Vaccine (2014) 32(43):5681-9. doi:10.1016/j.vaccine.2014.08.016

59. Lewis JS, Dolgova NV, Zhang Y, Xia CQ, Wasserfall CH, Atkinson MA, et al. A combination dual-sized microparticle system modulates dendritic cells and prevents type 1 diabetes in prediabetic NOD mice. Clin Immunol (2015) 160(1):90-102. doi:10.1016/j.clim.2015.03.023

60. Cho JJ, Stewart JM, Drashansky TT, Brusko MA, Zuniga AN, Lorentsen KJ, et al. An antigen-specific semi-therapeutic treatment with local delivery of tolerogenic factors through a dual-sized microparticle system blocks experimental autoimmune encephalomyelitis. Biomaterials (2017) 143:79-92. doi:10.1016/j.biomaterials.2017.07.029

61. Duong BH, Tian H, Ota T, Completo G, Han S, Vela JL, et al. Decoration of T-independent antigen with ligands for $\mathrm{CD} 22$ and Siglec-G can suppress immunity and induce B cell tolerance in vivo. J Exp Med (2010) 207(1): 173-87. doi:10.1084/jem.20091873

62. Macauley MS, Pfrengle F, Rademacher C, Nycholat CM, Gale AJ, von Drygalski A, et al. Antigenic liposomes displaying CD22 ligands induce antigen-specific B cell apoptosis. JClin Invest (2013) 123(7):3074-83. doi:10.1172/JCI69187

63. Yeste A, Nadeau M, Burns EJ, Weiner HL, Quintana FJ. Nanoparticlemediated codelivery of myelin antigen and a tolerogenic small molecule suppresses experimental autoimmune encephalomyelitis. Proc Natl Acad Sci US A (2012) 109(28):11270-5. doi:10.1073/pnas.1120611109

64. Yeste A, Takenaka MC, Mascanfroni D, Nadeau M, Kenison JE, Patel B, et al. Tolerogenic nanoparticles inhibit $\mathrm{T}$ cell-mediated autoimmunity through SOCS2. Sci Signal (2016) 9(433):ra61. doi:10.1126/scisignal.aad0612
65. Capini C, Jaturanpinyo M, Chang HI, Mutalik S, McNally A, Street S, et al. Antigen-specific suppression of inflammatory arthritis using liposomes. J Immunol (2009) 182(6):3556-65. doi:10.4049/jimmunol.0802972

66. Maldonado RA, LaMothe RA, Ferrari JD, Zhang AH, Rossi RJ, Kolte PN, et al. Polymeric synthetic nanoparticles for the induction of antigen-specific immunological tolerance. Proc Natl Acad Sci U S A (2015) 112(2):E156-65. doi:10.1073/pnas.1408686111

67. Zhang AH, Rossi RJ, Yoon J, Wang H, Scott DW. Tolerogenic nanoparticles to induce immunologic tolerance: prevention and reversal of FVIII inhibitor formation. Cell Immunol (2016) 301:74-81. doi:10.1016/j.cellimm.2015. 11.004

68. Meliani A, Boisgerault F, Ronzitti G, Collaud F, Leborgne C, Kishimoto TK, et al. 77. antigen-specific modulation of capsid immunogenicity with tolerogenic nanoparticles results in successful AAV vector readministration. Mol Ther (2016) 24:S34. doi:10.1016/S1525-0016(16)32886-6

69. Tostanoski LH, Chiu YC, Gammon JM, Simon T, Andorko JI, Bromberg JS, et al. Reprogramming the local lymph node microenvironment promotes tolerance that is systemic and antigen specific. Cell Rep (2016) 16(11):2940-52. doi:10.1016/j.celrep.2016.08.033

70. Lim HH, Yi H, Kishimoto TK, Gao F, Sun B, Kishnani PS. A pilot study on using rapamycin-carrying synthetic vaccine particles (SVP) in conjunction with enzyme replacement therapy to induce immune tolerance in Pompe disease. Mol Genet Metab Rep (2017) 13:18-22. doi:10.1016/j. ymgmr.2017.03.005

71. Mazor R, King EM, Onda M, Cuburu N, Addissie S, Crown D, et al. Tolerogenic nanoparticles restore the antitumor activity of recombinant immunotoxins by mitigating immunogenicity. Proc Natl Acad Sci U S A (2018) 115(4):E733-42. doi:10.1073/pnas.1717063115

72. Sands E, Kivitz A, Johnston L, Kishimoto T. THU0422 SEL-212: enhanced serum uric acid control in hyperuricemic patients through selective mitigation of anti-drug antibodies against pegsiticase. Ann Rheum Dis (2017) 76(Suppl 2):367. doi:10.1136/annrheumdis-2017-eular.3548

73. Huang L, Li L, Lemos H, Chandler PR, Pacholczyk G, Baban B, et al. Cutting edge: DNA sensing via the STING adaptor in myeloid dendritic cells induces potent tolerogenic responses. J Immunol (2013) 191(7):3509-13. doi:10.4049/jimmunol.1301419

74. Engman C, Wen Y, Meng WS, Bottino R, Trucco M, Giannoukakis N. Generation of antigen-specific Foxp3+ regulatory T-cells in vivo following administration of diabetes-reversing tolerogenic microspheres does not require provision of antigen in the formulation. Clin Immunol (2015) 160(1): 103-23. doi:10.1016/j.clim.2015.03.004

75. Casiraghi F, Cortinovis M, Perico N, Remuzzi G. Recent advances in immunosuppression and acquired immune tolerance in renal transplants. Am J Physiol Renal Physiol (2016) 310(6):F446-53. doi:10.1152/ ajprenal.00312.2015

76. Shirali AC, Look M, Du W, Kassis E, Stout-Delgado HW, Fahmy TM, et al. Nanoparticle delivery of mycophenolic acid upregulates PD-L1 on dendritic cells to prolong murine allograft survival. Am J Transplant (2011) 11(12):2582-92. doi:10.1111/j.1600-6143.2011.03725.x

77. Srivastava KD, Siefert A, Fahmy TM, Caplan MJ, Li XM, Sampson HA. Investigation of peanut oral immunotherapy with $\mathrm{CpG} /$ peanut nanoparticles in a murine model of peanut allergy. J Allergy Clin Immunol (2016) 138(2):536.e-43.e. doi:10.1016/j.jaci.2016.01.047

78. Bilati U, Allemann E, Doelker E. Poly(D,L-lactide-co-glycolide) proteinloaded nanoparticles prepared by the double emulsion method processing and formulation issues for enhanced entrapment efficiency. J Microencapsul (2005) 22(2):205-14. doi:10.1080/02652040400026442

79. Gu F, Zhang L, Teply BA, Mann N, Wang A, Radovic-Moreno AF, et al. Precise engineering of targeted nanoparticles by using self-assembled biointegrated block copolymers. Proc Natl Acad Sci U S A (2008) 105(7):2586-91. doi:10.1073/pnas.0711714105

80. Kuo R, Saito E, Miller SD, Shea LD. Peptide-conjugated nanoparticles reduce positive co-stimulatory expression and $\mathrm{T}$ cell activity to induce tolerance. Mol Ther (2017) 25(7):1676-85. doi:10.1016/j.ymthe.2017. 03.032

81. McCarthy DP, Yap JW, Harp CT, Song WK, Chen J, Pearson RM, et al. An antigen-encapsulating nanoparticle platform for TH1/17 immune tolerance therapy. Nanomedicine (2017) 13(1):191-200. doi:10.1016/j.nano 2016.09.007 
82. Casals E, Pfaller T, Duschl A, Oostingh GJ, Puntes V. Time evolution of the nanoparticle protein corona. ACS Nano (2010) 4(7):3623-32. doi:10.1021/ nn901372t

83. Gref R, Lück M, Quellec P, Marchand M, Dellacherie E, Harnisch S, et al. 'Stealth' corona-core nanoparticles surface modified by polyethylene glycol (PEG): influences of the corona (PEG chain length and surface density) and of the core composition on phagocytic uptake and plasma protein adsorption. Colloids Surf B Biointerfaces (2000) 18(3-4):301-13. doi:10.1016/ S0927-7765(99)00156-3

84. Kaminskas LM, Porter CJ. Targeting the lymphatics using dendritic polymers (dendrimers). Adv Drug Deliv Rev (2011) 63(10-11):890-900. doi:10.1016/j. addr.2011.05.016

85. Reddy ST, Rehor A, Schmoekel HG, Hubbell JA, Swartz MA. In vivo targeting of dendritic cells in lymph nodes with poly(propylene sulfide) nanoparticles. J Control Release (2006) 112(1):26-34. doi:10.1016/j. jconrel.2006.01.006

86. Reddy ST, van der Vlies AJ, Simeoni E, Angeli V, Randolph GJ, O’Neil CP, et al. Exploiting lymphatic transport and complement activation in nanoparticle vaccines. Nat Biotechnol (2007) 25(10):1159-64. doi:10.1038/ nbt1332

87. Manolova V, Flace A, Bauer M, Schwarz K, Saudan P, Bachmann MF. Nanoparticles target distinct dendritic cell populations according to their size. Eur J Immunol (2008) 38(5):1404-13. doi:10.1002/eji.200737984

88. Yi S, Allen SD, Liu YG, Ouyang BZ, Li X, Augsornworawat P, et al. Tailoring nanostructure morphology for enhanced targeting of dendritic cells in atherosclerosis. ACS Nano (2016) 10(12):11290-303. doi:10.1021/ acsnano.6b06451

89. Gerner MY, Torabi-Parizi P, Germain RN. Strategically localized dendritic cells promote rapid $\mathrm{T}$ cell responses to lymph-borne particulate antigens. Immunity (2015) 42(1):172-85. doi:10.1016/j.immuni.2014.12.024

90. Schietinger A, Greenberg PD. Tolerance and exhaustion: defining mechanisms of T cell dysfunction. Trends Immunol (2014) 35(2):51-60. doi:10.1016/j.it.2013.10.001

91. Yu W, Freeland DMH, Nadeau KC. Food allergy: immune mechanisms, diagnosis and immunotherapy. Nat Rev Immunol (2016) 16(12):751-65. doi:10.1038/nri.2016.111

92. Getts DR, McCarthy DP, Miller SD. Exploiting apoptosis for therapeutic tolerance induction. JImmunol (2013) 191(11):5341-6. doi:10.4049/ jimmunol.1302070

93. Pasparakis M, Vandenabeele P. Necroptosis and its role in inflammation. Nature (2015) 517(7534):311-20. doi:10.1038/nature14191

94. Pearson RM, Casey LM, Hughes KR, Miller SD, Shea LD. In vivo reprogramming of immune cells: technologies for induction of antigen-specific tolerance. Adv Drug Deliv Rev (2017) 114:240-55. doi:10.1016/j.addr.2017.04.005

95. Pearson RM, Casey LM, Hughes KR, Wang LZ, North MG, Getts DR, et al. Controlled delivery of single or multiple antigens in tolerogenic nanoparticles using peptide-polymer bioconjugates. Mol Ther (2017) 25(7):1655-64. doi:10.1016/j.ymthe.2017.04.015

96. Kontos S, Kourtis C, Dane KY, Hubbell JA. Engineering antigens for in situ erythrocyte binding induces T-cell deletion. Proc Natl Acad Sci U S A (2013) 110(1):E60-8. doi:10.1073/pnas.1216353110

97. Birge RB, Boeltz S, Kumar S, Carlson J, Wanderley J, Calianese D, et al. Phosphatidylserine is a global immunosuppressive signal in efferocytosis, infectious disease, and cancer. Cell Death Differ (2016) 23(6):962-78. doi:10.1038/cdd.2016.11

98. Gaitonde P, Ramakrishnan R, Chin J, Kelleher RJ Jr., Bankert RB, Balu-Iyer SV. Exposure to factor VIII protein in the presence of phosphatidylserine induces hypo-responsiveness toward factor VIII challenge in hemophilia a mice. J Biol Chem (2013) 288(24):17051-56. doi:10.1074/jbc.C112.396325

99. Yau FC, Balu-Iyer SV. Effect of an active phosphatidylserine species on antigen-specific tolerance induction towards factor VIII in hemophilia a mice. FASEB J (2017) 31(1 Suppl):674.610.

100. Natarajan S, Thomson AW. Tolerogenic dendritic cells and myeloid-derived suppressor cells: potential for regulation and therapy of liver auto- and alloimmunity. Immunobiology (2010) 215(9-10):698-703. doi:10.1016/j. imbio.2010.05.024

101. Thomson AW, Knolle PA. Antigen-presenting cell function in the tolerogenic liver environment. Nat Rev Immunol (2010) 10(11):753-66. doi:10.1038/ nri2858

102. Adorini L, Giarratana N, Penna G. Pharmacological induction of tolerogenic dendritic cells and regulatory T cells. Semin Immunol (2004) 16(2):127-34. doi:10.1016/j.smim.2003.12.008

103. Svajger U, Obermajer N, Jeras M. Novel findings in drug-induced dendritic cell tolerogenicity. Int Rev Immunol (2010) 29(6):574-607. doi:10.3109/088 30185.2010.522280

104. Turnquist HR, Fischer RT, Thomson AW. Pharmacological modification of dendritic cells to promote their tolerogenicity in transplantation. Methods Mol Biol (2010) 595:135-48. doi:10.1007/978-1-60761-421-0_8

105. Thomson AW, Turnquist HR, Raimondi G. Immunoregulatory functions of mTOR inhibition. Nat Rev Immunol (2009) 9(5):324-37. doi:10.1038/ nri2546

106. Perl A. Activation of mTOR (mechanistic target of rapamycin) in rheumatic diseases. Nat Rev Rheumatol (2016) 12(3):169-82. doi:10.1038/ nrrheum.2015.172

107. LaMothe RA, Kolte P, Vo T, Ferrari JD, Gelsinger TC, Wong J, et al. Tolerogenic Nanoparticles Induce Antigen-Specific Regulatory $\mathrm{T}$ Cells and Provide Therapeutic Efficacy and Transferrable Tolerance against Experimenta Autoimmune Encephalomyelitis. Front Immunol (2018) 9:281. doi:10.3389/ fimmu.2018.00281

108. Pang L, Macauley MS, Arlian BM, Nycholat CM, Paulson JC. Encapsulating an immunosuppressant enhances tolerance induction by siglec-engaging tolerogenic liposomes. Chembiochem (2017) 18(13):1226-33. doi:10.1002/ cbic. 201600702

Conflict of Interest Statement: Both RM and TK are employees and shareholders of Selecta Biosciences Inc., a company developing tolerogenic nanoparticles.

The handling editor and reviewer HW declared their involvement as coeditors in the Research Topic, and confirm the absence of any other collaboration.

Copyright (C) 2018 Kishimoto and Maldonado. This is an open-access article distributed under the terms of the Creative Commons Attribution License (CC BY). The use, distribution or reproduction in other forums is permitted, provided the original author(s) and the copyright owner are credited and that the original publication in this journal is cited, in accordance with accepted academic practice. No use, distribution or reproduction is permitted which does not comply with these terms. 